\title{
Analysis of New Type Elevating Mechanism for Hybrid Forklift Based on
}

\author{
ANSYS \\ Wang Yao ${ }^{1,2, a}$, Zhao Dingxuan ${ }^{1, b, *}$, Wang Lei ${ }^{1, c}$, Wang Lili, ${ }^{1, d}$, Hu Yanjuan ${ }^{3, e}$ \\ 1.College of Mechanical Science and Engineering,JilinUniversity,Changchun,China \\ 2.College of Mechanical Engineering, BeihuaUniversity,Jilin,China \\ 3.School of Mechatronic Engineering, Changchun University of Technology,Changchun,Chinah \\ a1724939466@qq.com, ${ }^{\text {,** } z d x @ j l u . e d u . c n, ~}{ }^{\circ} 526794044 @ q q . c o m,{ }^{d} 1483084809 @ q q . c o m$, \\ e37894293@qq.com
}

Key words: hybrid technology; forklift; elevating mechanism; simulation analysis

Abstract: A new kind of elevating mechanism for hybrid forklift has been designed. The 3D modeling for the upright mounting is using CATIA 3D software. And then, the elevating mechanism for hybrid forklift was simulated by the finite element analysis software ANSYS. Under different working conditions, such as upright mounting load upright mounting rise or upright mounting decline, maximum deformation extent and deformation stress points were analyzed. By analyzing, maximum deformation extent and deformation stress points are within a reasonable range, a new type elevating mechanism for hybrid forklift suffices requirement of the design.

\section{Introduction}

With the development of technology and development of the market economy, harbor transportation and logistics warehousing are blooming. Although as compared with developed countries, logistics warehousing is still in the initial stage in our country. The State Department's "The National Development Planning of Logistics Park (2013-2020)" was unveiled in 2013, the development of logistics warehousing has risen to the national strategic level. The policies shall be further carried out so as to decrease the logistics park operating cost and bring benefits to logistics companies. Infrastructure development and perspective of equipment makers, such as forklift、crane are directly related to logistics will rise. Logistics equipment plays a more and more important role in economic development $[1,2]$.

As harbor transportation and logistics warehousing developed, the demand of forklift has been rising rapidly in recent years [3, 4]. Forklift, a high-efficiency equipment of mechanized handling and short distance stransportation, which was used for stations, ports, airports, factories, warehouses, received high-speed development with the release of China's consumption potential and further integration of the logistics industry norms surely usher in rapid development period[5]. 


\section{Constructing finite-elemental modal}

3D modeling of elevating mechanism for hybrid forklift for the upright mounting is using CATIA 3D software. Then, the 3D models of the upright mounting by using CATIA software are saved as STP files. The upright mounting of 3D models are imported into ANSYS, and then to accomplish import of the upright mounting of 3D models. After importing the model, because it's structural characteristics is complex, using the method of smart division and local refinement to plot numbered cell mesh.

After mast mesh model, a total of 125,331 nodes, 84,838 units, as shown in Fig.1.

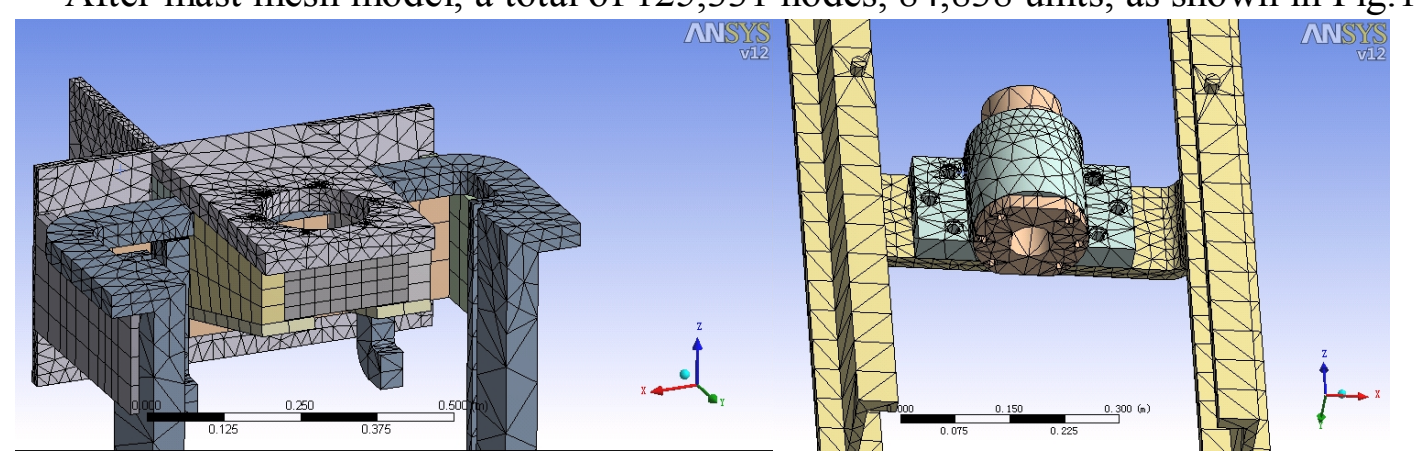

Fig. 1 mast mesh model

\section{Finite element analysis of elevating mechanism for hybrid forklift}

The upright mounting of hybrid forklift applied load is measured by two different work conditions. According to the different work conditions, outer upright mounting inner upright mounting and ball screw assembly are respectively analyzed.

When the fork pickup remains stationary, to inner, outer upright mounting and the ball screw pair static force analysis. Applying $90000 \mathrm{~N}$ on nut of the ball screw pair under static load, the outer door frame stress deformation and stress analysis as shown in Fig.2 and Fig.3. The maximum deformation in supporting part of the ball screw, amount of deformation is $0.00040581 \mathrm{~m}$. The maximum stress in bolt holes of flange, stress value is $111.71 \mathrm{MPa}$. The inner upright mounting stress deformation and stress points analysis as shown in Fig.4 and Fig.5. The maximum deformation in the ball screw nut seat, amount of deformation is $0.00041317 \mathrm{~m}$. The maximum stress in bolt hole of the ball screw nut seat, stress value is $140.88 \mathrm{MPa}$.Ball screw pair stress deformation and stress points analysis as shown in Fig. 6 and Fig.7.The maximum deformation in supporting part of the ball screw, amount of deformation is $0.00096714 \mathrm{~m}$, the maximum stress point is located on the part of ball makes contact with screw, stress value is $164.95 \mathrm{MPa}$.

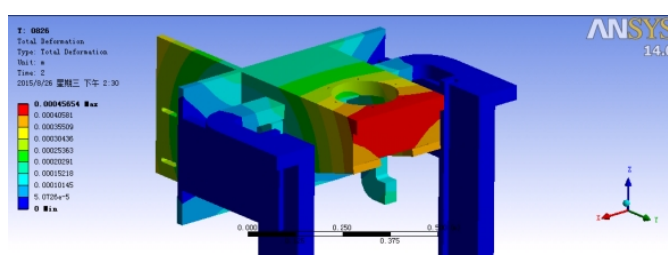

Fig. 2 total deformation

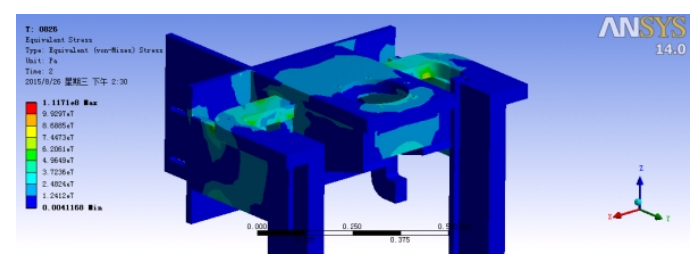

Fig.3 equivalent stress 


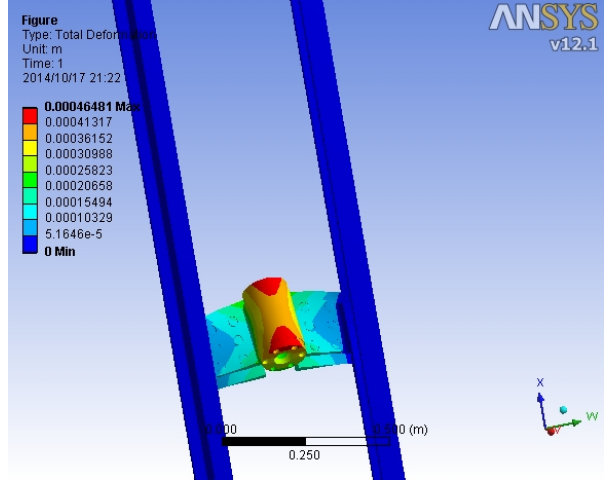

Fig.4 total deformation

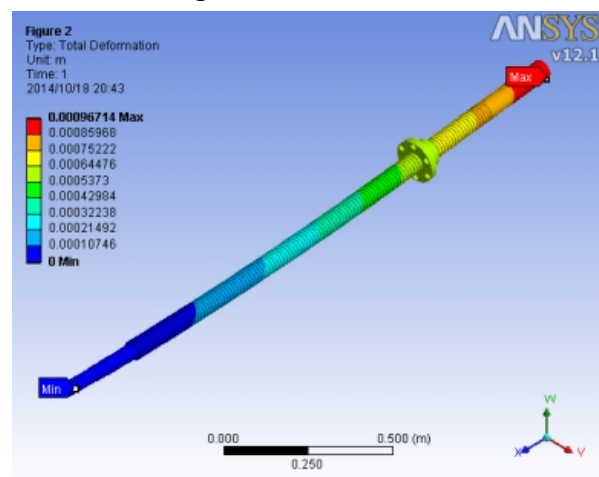

Fig.6total deformation

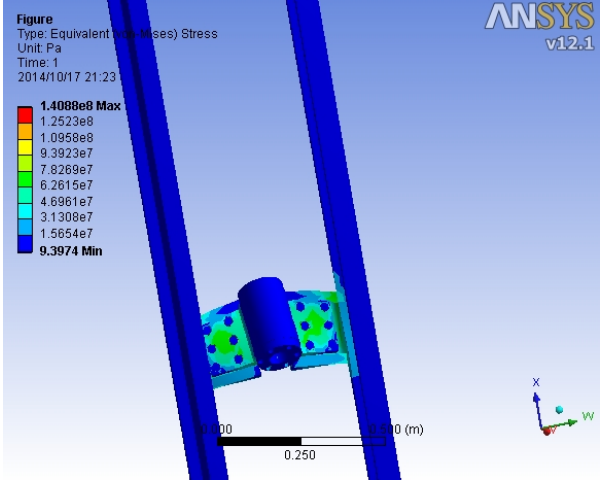

Fig. 5 equivalent stress

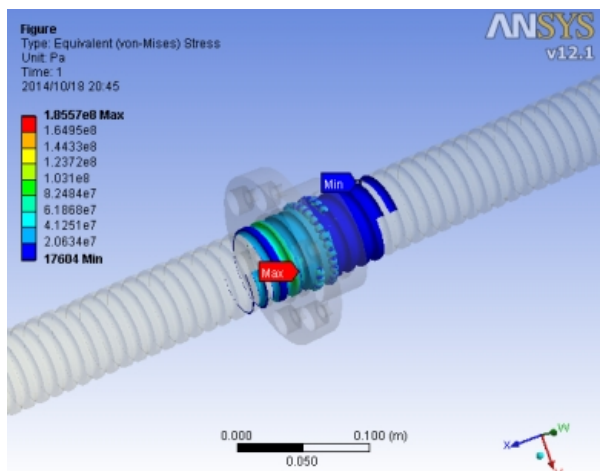

Fig.7 equivalent stress

When the process of cargo lifting emergency stop ,the inner、outer upright mounting and the ball screw pair will be large impact pressure. It is particularly important, therefore, for the inner upright mounting stress to be analyzed. Applying $100000 \mathrm{~N}$ dynamic load in the nut of the ball screw pair, the duration was $1 \mathrm{~s}$, the outer upright mounting stress deformation and stress analysis as shown in Fig.8 and Fig.9. The maximum deformation in supporting part of the ball screw, amount of deformation is $0.00052027 \mathrm{~m}$, The maximum stress in bolt holes of flange, stress value is 196.66MPa. The inner upright mounting stress deformation and stress analysis are as shown in Fig. 10 and Fig.11. The maximum deformation in the ball screw nut seat, amount of deformation is $0.0034366 \mathrm{~m}$, the maximum stress point is located in the inner upright mounting web, and stress value is $1040.4 \mathrm{MPa}$. Ball screw pair stress deformation and stress points analysis are as shown in Fig.12 and Fig.13. The maximum deformation in supporting part of the ball screw, amount of deformation is $0.0010746 \mathrm{~m}$, the maximum stress point is located on the part of ball makes contact with screw, stress value is $206.19 \mathrm{MPa}$.

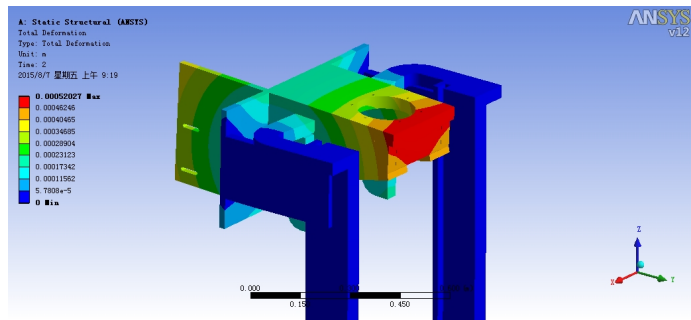

Fig.8 total deformation

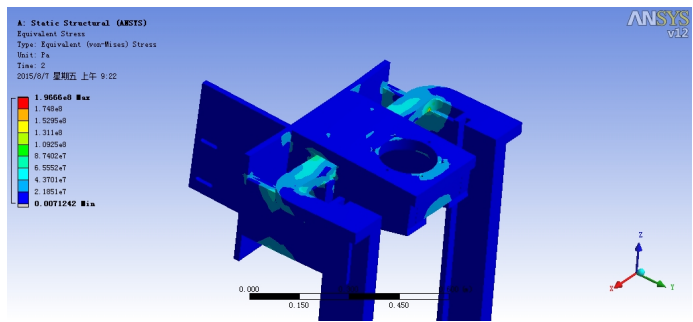

Fig.9 equivalent stress 


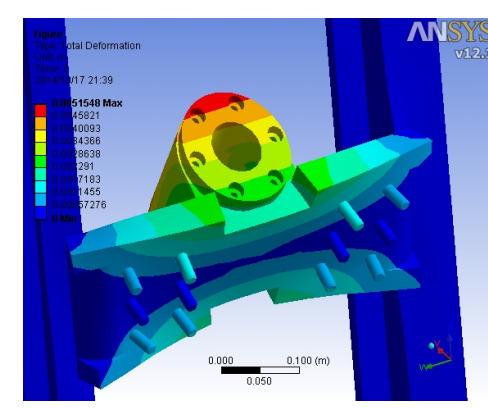

Fig.10 total deformation

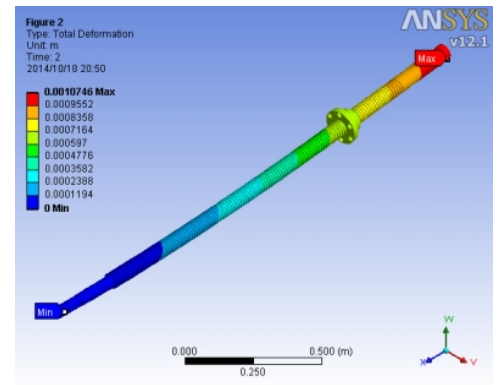

Fig.12 total deformation

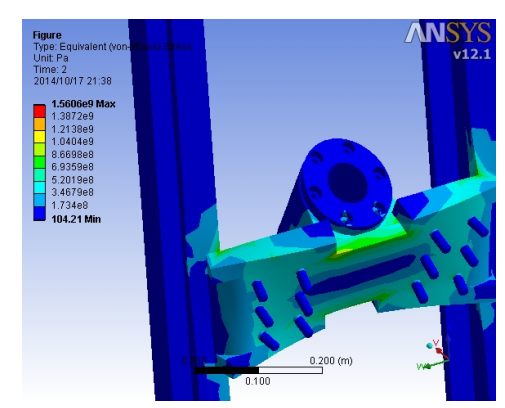

Fig.11 equivalent stress

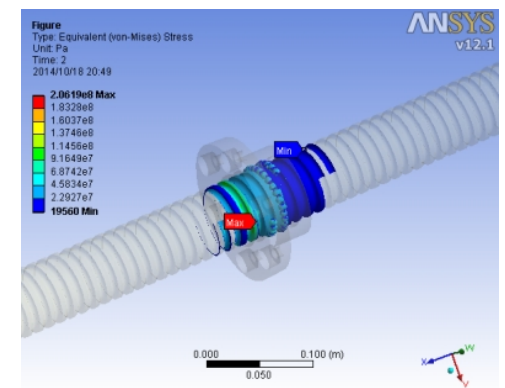

Fig. 13 equivalent stress

\section{Conclusions}

A new hybrid forklift lifting mechanism was designed. It can be seen through the analysis, the amount of stress deformation and stress distribution hybrid forklift mast lifting mechanism are qualified in both work conditions. And it provides a theoretical basis for the subsequent hybrid forklift overall design and experimentation.

\section{Acknowledgment}

The research is funded by National High Technology Research and Development Program 863(2009AA044403) and 985 Program of Jilin University.

\section{References}

[1] Y.Y. ZHAO, D. ZHANG. The Key Technologies Analysis Of Hybrid Construction Machinery. Equipment Manufacturing Technology, 8(2014) 254-255 (In Chinese).

[2] C.L. Li, H. Zhao, Q.F. Ma. Study on Forward-Facing Modeling and Simulation for Hybrid Electric Forklift. Machinery Design \& Manufacture, 10(2013) 80-83(In Chinese).

[3] Q.N. Wang, Z.R. Liu, W.H. Wang. Modeling and simulation of hybrid electric vehicles. Automotive Engineering, 27(2005) 392-394(In Chinese).

[4] Z.H. Jin, X. Xu. Present Situation of Electric Forklifts and Their Developing Trend. Construction Machinery and Equipment, 10(2014) 37-38 (In Chinese).

[5] Y.Q. Xiao. The trend of technology development of forktruck. Port Operation, 2(2007) 11-15(In Chinese). 